\title{
Singularidade e mito: o corpo como potência subversiva
}

\section{Singularity and myth: the body as a subversive power}

\author{
Marina Pinheiro*1 \\ Glória Carvalho*2
}

\begin{abstract}
Através da investigação sobre o campo enunciativo próprio aos sujeitos que realizam modificações corporais extremas (construção da imagem corporal distinta do padrão clássico ocidental, com uso excessivo de técnicas como a tatuagem, piercing e cirurgia plástica), o presente artigo problematiza a singularidade, tomando-a como uma formação mítico-imaginária na qual a unicidade do ser seria não só um ancoradouro identitário, mas também uma expressão possível do desejo de tornar-se o poeta forte de sua história.
\end{abstract}

Palavras-chave: Singularidade, sujeito dividido, modificações corporais extremas, mito

${ }^{* 1}$ Universidade Federal de Pernambuco - UFPE (Recife, PE, Br).

*2 Universidade Católica de Pernambuco - Unicap (Recife, PE,Br) 


\section{ARTIGOS}

\section{Introdução}

A singularidade é tema dos mais valiosos nos estudos sobre a subjetividade. Seu valor é efeito de quando concebemos que é num permanente movimento de diferenciação em relação ao outro, par na cultura, que o sujeito pode advir. A expressão "nome próprio", por exemplo, parece bem representar a condição singularizante da subjetividade. O nome, como um significante que é transmitido, abriga uma história e uma pré-história; um lugar simbólico ao qual somos lançados. Tributário do campo desejante do outro parental, este nome também há de ser "próprio", há de se operar uma nova história através dele, uma subversão única e inescapável ao ser.

Seria nesse sentido que problematizar sobre como nos tornamos sujeitos de linguagem apenas pela via do que nos é ofertado/demandado pela cultura é condição necessária, mas não suficiente para o entendimento da condição humana. É preciso investir na dimensão singular daquilo que é posto como dado, enquanto modo de nos aproximarmos do dinamismo transformador - gerador do novo, da diferença - como ocorre no âmbito da vida, das artes e da produção do conhecimento. Se tomarmos o trabalho de generalização como processo discursivo que visa encontrar homogeneidades, semelhanças, ou ainda, um traço/aspecto por meio do qual as individualidades são postas sob o circuito do mesmo, a singularidade aludiria ao que se ofereceria como resistência, dimensão subversiva do movimento de homogeneização nas ciências. 
O presente artigo pretende contribuir para a compreensão dos sentidos e das implicações que a singularidade humana pode vir a desenvolver no modo como lemos processos de subjetivação. ${ }^{1}$ É, portanto, reconhecendo a insuficiência de lermos na singularidade apenas um conjunto de características individuais, ou, ainda, uma simplória diferença em relação às regularidades esperadas em grupos humanos, que essa reflexão recebeu seu primeiro fôlego de escrita.

Foi portanto reconhecendo a relevância de indagar acerca de como a singularidade acontece no tornar-se sujeito, que a prática de extremas modificações corporais (extreme body modifications) é tomada como campo enunciativo à elaboração proposta. Essas manipulações da imagem corporal são realizadas por grupos de pessoas que, estranhando e relutando à forma física dada pela espécie, transformam a imagem de si como modo de se aproximar de um "verdadeiro eu", supostamente único e imaginariamente autofundado, para além e aquém de quaisquer heranças históricas. Para esse grupo, aquilo que é lido como sua singularidade, uma suposta radical diferença em relação ao outro, é objeto fundamental do projeto corporal estetizante de si, a ser inscrito na pele. Mediante implantes subcutâneos de silicone das mais diversas formas, tatuagens (realizadas com tinta, queimaduras ou remoção da camada superficial da pele com bisturi), bipartição de língua, suspensões do corpo pela colocação de anzóis que içam a pele, piercings e alargadores (de orelha ou narina), as pessoas que realizam essas ações as proclamam como um exercício de plena libertação de coerções sociais, expressão de uma potência entendida como de autocriação diferenciadora e resistente ao mercado de estilos contemporâneos. Desse modo, salienta-se que, por via desse cenário discursivo, pretende-se destacar duas dimensões sobre as gramáticas da singularidade postas aqui em discussão, a saber: o possível lugar que a singularidade ocupa no imaginário de nossa época, em sua interface com a privilegiada função que a corporeidade parece assumir nos processos identitários da atualidade, assim como a problematização sobre

${ }^{1}$ Por processo de subjetivação alude-se, no presente artigo, à trama histórica, cultural e epistemológica próprias às condições de possibilidade de constituição do sujeito, ou, ainda, de seu tornar-se (Foucault, 1992; Birman, 1996; Costa, 2004). Em outras palavras, tal processo se daria pela dinâmica das relações de saber-poder inerentes às culturas na produção de formas de vida. 


\section{ARTIGOS}

como a singularidade - como um processo metapsicológico-especular dar-se-ia operando transformações de sobredeterminação inconsciente ${ }^{2}$ para com a possível singularidade idealizada nos discursos de nossa cultura.

Destaca-se que a discussão proposta no presente artigo baseia-se na pesquisa realizada por Pinheiro (2011), "Singularidade e corpo: uma questão para a subjetividade". Nessa investigação, foram utilizados três "relatos de si" (narrativas autobiográficas), escritos por praticantes de extremas modificações corporais e disponibilizados em uma revista virtual denominada bmezine.com (body modification ezine; publicada desde 1994). Essa revista é uma das principais mídias de divulgação da body art, uma referência em termos de publicação das mais diversas e numerosas experiências de manipulações corporais. Desta forma, inspirada por uma análise de discurso de orientação lacaniana (Cuéllar, 2010) a autora problematizou questões como: 1) De que modo o corpo e suas transformações são aludidos no processo de diferenciação sinalizado nos relatos?; 2) Entre a diferença própria à ilusão de unidade imaginária do eu, e a diferença descentradora do si próprio, como os relatos dos praticantes encenam essa tensão?

É, portanto, a partir do levantamento bibliográfico e da discussão dos dados de Pinheiro (2011) que o argumento do presente artigo é desenvolvido, buscando, assim, desnaturalizar os usos e perspectivar novos sentidos para a gramática da singularidade na compreensão da subjetividade de nosso tempo. As próximas páginas deste trabalho são divididas em dois momentos, sendo o primeiro mais voltado para uma possível dimensão mítica da singularidade e um segundo, de maior ênfase metapsicológica, voltado para novas possibilidades interpretativas da relação entre corpo e singularidade.

\section{O suicídio emocional da conformidade}

Eu realmente apenas comecei com a ideia de toda modificação corporal, quando decidi que nunca queria ser um membro normal da sociedade.

${ }^{2} \mathrm{O}$ termo sobredeterminação inconsciente refere-se ao dinamismo próprio à ordem significante, “(...) e, portanto, constituído, por natureza, de deslizes e de sobreposição de sentidos; nunca é sinal unívoco de um conteúdo inconsciente único, assim como a palavra não se pode reduzir a um sinal" (Laplanche \& Pontalis, 1998, p. 489). 
Suponho que depois que eu deixei a prática jurídica e me dei a permissão de correr o risco do desemprego, pois a minha liberação corporal era mais importante que o suicídio emocional da conformidade. (T. Angel, 2010) ${ }^{3}$

$\mathrm{Na}$ epígrafe supracitada, extraída do relato de Eldge em entrevista ao blogger T. Angel, deparamo-nos com uma expressão que aparenta posicionar-se como um forte ancoradouro discursivo para a emergência das extremas modificações corporais; a saber: "o suicídio emocional da conformidade". O horror à normalidade, à dimensão ordinária da existência, ou, ainda, ao ser "mais um na multidão" é enunciado como risco de mortificação subjetiva, apagamento de uma diferença fundamental e constitutiva da relação eu-outro.

A recorrência dessa espécie de recusa radical ao ordinário é, como experiência prototípica do grupo, assumida como temor ao mesmo tempo contingente, relativo às especificidades de nossa cultura, e universal, próprio ao que de arcaico em nossa constituição insiste em se atualizar.

É pelas vias de sua temporalidade regressiva e diferencial - bem como pela sua dimensão linguageira e imaginária ${ }^{4}$ — que a presente discussão sobre

${ }^{3}$ Recuperado em 29 out. 2017 de: <http://www.frrrkguys.com.br/ modifique-seu-corpo-e-modifique-o-mundo $>$.

${ }^{4}$ Segundo Vanier (2005): "O Simbólico remete simultaneamente à linguagem e à função compreendida por Claude Lévi-Strauss como aquela que organiza a troca no interior dos grupos sociais; o Imaginário designa a relação com a imagem do semelhante e com o 'corpo próprio'; o Real, que deve ser distinguido da realidade, é um efeito do Simbólico: o que o simbólico expulsa, instaurando-se” (pp. 18-19). Esta citação indica que se pode conceber o real como o indizível desse corpo sensorial inconsciente, essa mensagem idiopática que se mantém como um resto excluído pelo simbólico. O imaginário seria uma dimensão totalizadora do eu, que ao mesmo tempo em que provoca o gozo da unidade ao que era disperso, também presentifica o horror pela objetificação do ser como escravo/servo dos investimentos de indiferenciação oriundos do sujeito do desejo (dividido). O simbólico, por fim, seria a dimensão que instaura o sujeito no campo da linguagem, quebra a imagem especular, lançando o ser no campo da Lei, impulsionadora da subjetividade no indeterminismo metonímico dos objetos de satisfação do desejo. Sem dúvida, a caracterização dos registros do real, do simbólico e do imaginário desenvolvida nessa citação não resgatam o dinamismo e a complexidade do nó borromeu. Entretanto, realiza-se, na brevidade dessa passagem, apenas um sentido de apoio à leitura. Espera-se que o texto, como um todo, possa resgatar a mobilidade dessa diferenciação das instâncias, na dinâmica metapsicológica humana. 


\section{ARTIGOS}

a singularidade requer, necessariamente, que a problematizemos em sua face mítica. Em linhas gerais, foi através da impactação provocada pelo apelo recorrente à legitimação da diferença singular pelas marcações corporais que algo da ordem de um semidito, partilhado no campo da cultura, solicita trabalho de interpretação.

Num primoroso artigo chamado "Anchoring the (Postmodern) Self? Body modification, fashion and identity", o sociólogo Paul Sweetman (1999) desenvolve uma ampla discussão acerca da popularização e da função simbólicosocial das tatuagens e piercings no discurso da subjetividade contemporânea. Por meio de um extenso número de entrevistas com sujeitos que portavam níveis de intensidade diversa de modificações corporais, o referido autor entra em franca discordância com certa perspectiva interpretativa que lê esse fenômeno como mera expressão de uma cultura que primaria por um "carnaval de signos" sem nenhum significado associado; um espetáculo de significantes que não se referem a nada além de si próprios; um objeto de consumo próprio ao mercado atual de estilos que faz apelo à apropriação de uma autenticidade industrializada e, assim, desprovida de qualquer efeito subversivo.

Para Sweetman (1999) a irreversibilidade, o longo processo de escolha da imagem e do local das marcações corporais, como também a dor envolvida nos respectivos procedimentos de modificação corporal, já dariam pistas de que a natureza de tais práticas estaria longe de se assemelharem à mera prática do consumo, tipicamente associadas ao imediatismo, à descartabilidade e à impulsividade características da apropriação de objetos do mercado. Nesse artigo, o aspecto mais destacado da análise da fala dos sujeitos dá-se na condição amplamente generalizada da função de "ser diferente", "original" e do "estar fora do ordinário" como resposta à pergunta sobre o que seria dotado de maior valor acerca de ser tatuado ou portador de piercings.

Num contexto histórico marcado por inseguranças, em que a crença em nossos próprios enunciados torna-se fragilizada, a prática das extremas marcações corporais se constituiria como recurso fundamental à construção de uma consistência autonarrativa. É como se as tatuagens funcionassem como uma espécie de diário, a salvo de qualquer risco de furto ou extravio.

Um diário, como registro biográfico, é enunciado na fala como um objeto passível de constante destituição, sob constante ameaça de perda. Só impressa na carne, a história nele contada estaria a salvo de sua vulnerabilidade face ao outro. Nessa perspectiva, a dita consistência parece aludir à condição de sustentação imaginária do eu que se apoia no universo dos enunciados herdados e transmitidos pela relação eu-Outro. 
Entre o Outro, ameaça de destituição do eu, e o outro que legitima e transmite a diferença rubricada sobre a carne, a metáfora atualiza um embate fundamental à singularidade discursiva do sujeito e, simultaneamente, um embate arcaico, regressivo, a que nenhum só homem escapa (Pinheiro, 2009).

É própria da metáfora essa condição de encenar, no campo do equívoco da língua, o indizível da experiência, mas que, concomitantemente, é impossível de se fazer calar, insiste em emergir como enunciação. No trabalho de dar forma ao amorfo, a metáfora é a palavra de uma verdade desejante desprovida de qualquer possibilidade de objetivação. É por meio dela que um campo estrangeiro à racionalidade do enunciado faz fenda na dinâmica de estabilização sígnica.

A verdade de que se trata é exatamente como a imagem mítica que a representa. Isso é, alguma coisa escondida na natureza e que depois sai com a mesma naturalidade, sai do poço. Isso sai não é o bastante, isso diz. (Lacan, 1981/2008, p. 23)

Por este caminho, as metáforas produzidas pelos praticantes de extremas modificações corporais parecem falar de um universo que se estende bem além da especificidade do sentido da escolha das marcas ou ainda de suas causações biográficas.

O mito é o que dá formulação discursiva a algo que não pode ser transmitido na definição de verdade, porque a definição de verdade só pode se apoiar sobre si mesma, e é na medida em que a fala progride que ela a constitui. A fala não pode apreender a si própria, nem apreender o movimento de acesso à verdade como uma verdade objetiva. Pode apenas exprimi-la — e isso de forma mítica. Neste sentido é que se pode dizer que aquilo em que a teoria analítica concretiza a relação intersubjetiva, e que é o complexo de Édipo, que tem valor de mito. (Lacan, 1981/2008, p. 13)

Nesse sentido, o mito, especialmente o edipiano, desempenha a função de ser uma especial forma de linguagem, a única possível, para se dizer a natureza estrutural dos conflitos intransponíveis da subjetividade, a dimensão simbólico-arqueológica do inconsciente e as relações fundamentais do ser humano. Assim, se tomado como efeito da linguagem, ou, ainda, como efeito do inconsciente estruturado como uma linguagem, o mito situa-se enquanto uma espécie de ficção perscrutada através da repetição de significantes e das organizações discursivas específicas de uma dada geração. De modo sucinto, a dimensão mítica da existência seria "uma forma de saber que nos atravessa sem que o saibamos" (Souza \& Rocha, 2009, p. 1999). 


\section{ARTIGOS}

A psicanálise teria seu lugar cultural ao produzir, na singularidade da escuta de cada caso, a reconstrução do que de arcaico e universal tenha sido silenciado pela temporalidade psíquica do recalque, bem como pela temporalidade histórica do desenvolvimento da civilização. "Na conjuntura individualista, cada sujeito busca em sua história individual (tempo perdido da infância) as raízes de seu sofrimento e de suas dúvidas, não na coletividade como o fazem as "sociedades primitivas" (Correia, 2001, p. 4). Pelo estatuto das fantasias na constituição do sujeito, a psicanálise tornara-se o campo mister das arqueologias do desejo, dos destinos singularizados no próprio homem para as inscrições hieroglíficas do Outro.

Num primeiro momento dessa construção, é válido retomar mais um fragmento da entrevista de Eldge anteriormente citado.

Eu não sou 'transgênero' como em querer ser/sentir-se como uma garota. Porém, eu me sinto 'transgênero' como significando de 'gênero transcendente'. Acho que algum tipo de rótulo seria 'gênero masculino não conformista com fundo agressivo'. Ou talvez apenas 'pervertido'. Isso quer dizer que eu não quero seios 'reais', mas eu amo ter os implantes. Pra mim é realmente sobre a perversão: é como uma perversidade sexual, política e emocional, relacionada a ser um garoto com seios falsos e um pinto grande demais para ser usado! ( $\mathrm{T}$. Angel, 2010, parágrafo 8)

O entrevistado aborda, assim, a precariedade das categorias identitárias de certa tradição na descrição de si. Seu "projeto corporal" (expressão empregada por diversos praticantes da body modification) inclui, além dos seios, implantes de significativa quantidade de silicone nos testículos e pênis, de modo a tornar os órgãos genitais inviabilizados para o ato sexual. Em algumas fotografias, a genitália é adornada com cordas e couro, assemelhando o pênis a uma luva de boxe.

Ter um "gênero transcendente", inconforme, na leitura dos nomes que empresta a si, parece indicar a incapacidade em caber neles, a marca da fragilidade da linguagem em poder dizer de sua verdade. Na sequência de enunciados, a "perversão" emerge como um possível nome mais apaziguador para exprimir o desmedido de seu desejo pela subversão. Seios que são falsos e amados em seu embuste, pênis que não pode ser usado; um corpo que parece ter sido projetado para encarnar a perversão do biológico pela linguagem.

Em sua luta por uma libertação dos vocabulários identitários tradicionais, em seu sonho pela transcendência dos lugares simbólicos a que foi lançado pela condição humana, a singularidade almejada por Eldge e descrita como traço único de seu projeto corporal, não deixa de metaforizar, ao mesmo 
tempo, um mal-estar inexorável, universal a todos os homens. Conforme proposto por Slavoj ZiZek, no artigo "Tolerance as an ideological category" (2007):

Universalidade não é o sentimento "profundo" de que para além de todas as diferenças, diferentes civilizações compartilham dos mesmos valores básicos; etc., a real universalidade (se atualiza) como a experiência de negatividade, de inadequação a si mesma, a uma identidade particular. A fórmula da solidariedade revolucionária não é "vamos tolerar as nossas diferenças", isto não é um pacto de civilizações, mas um pacto de lutas que atravessa as civilizações, um pacto entre o quê, em cada civilização, mina sua própria identidade (...) O que nos une é a mesma luta (...) isto é, a universalidade que se transforma por si mesma em uma violenta experiência do sujeito que se torna consciente de que ele não é completamente pleno de si mesmo (coincidindo com a sua forma particular de existência), que ele é marcado por uma profunda divisão. (p. 4$)^{5}$

A propósito de exemplificação de seu pensamento, Zizek (2007) comenta uma pergunta que frequentemente era endereçada a Primo Levi (citado por Zizek), escritor judeu italiano que sobreviveu ao campo de concentração de Auschwitz. Quando indagado se se considerava primeiramente um judeu ou humano, Levi oscilava entre as duas escolhas. Para Zizek, a resposta mais consistente não seria a de que Levi seria primeiramente um humano que teria acontecido de tornar-se judeu. Levi seria humano precisamente e apenas até onde ser judeu era um problema para ele e não um fato ou, ainda, até onde ele não poderia reconhecer-se completamente enquanto judeu.

Mediante a proposição acima apontada, a questão de Eldge redimensiona-se como enigma atemporal do tornar-se sujeito, efeito de nossa inescapável divisão. A inconformidade é assim representante de uma descentração radical, para a qual nossos mitos individuais advêm como tentativa de

${ }^{5}$ Citação original: "Universality is not the 'deep' feeling that above all differences, different civilizations share the same basic values; etc.; actual universality (actualizes itself) as the experience of negativity, of the inadequacy-to-itself, of a particular identity. The formula of revolutionary solidarity is not 'let us tolerate our differences', it is not a pact of civilizations, but a pact of struggles which cut across civilizations, a pact between what, in each civilization, undermines its identity (...) What unite us is the same struggle. (...) it is the universality which becomes for itself in a violent experience of the subject who becomes aware that he is not fully himself (coinciding with his particular form of existence), that he is marked by a profound split (p. 4). 


\section{ARTIGOS}

organização ao que insiste em se colocar como questão. Nesse sentido, da fala disparada pelo diário tatuado na pele à masculinidade inconformista esculpida por Eldge, podemos reconhecer certo modo de encenar, no campo da cultura, novos destinos à incompletude estrutural.

Nos relatos dos praticantes das modificações corporais extremas, é expressivo o embate narrativo centrado na afirmação da legitimidade da diferença, da singularidade do "corpo-rubrica", histórica de si. No conflito imaginário-especular junto ao outro, a excepcionalidade da imago corporal se oferece como uma possível resposta a uma alteridade normativa, castradora, arbitrária e, sobretudo, detratora da autenticidade única e desejante.

Essa formação discursiva provoca certo efeito de semelhança ao discurso do personagem Roquentim, do romance $A$ náusea (Sartre, 1938/2005). Esse personagem - protagonista e narrador da novela - descreve, num tipo de diário, sua aversão à alienação cotidiana dos habitantes da cidade de Bouville, cidade para onde retornara com a finalidade inicial de desenvolver uma pesquisa sobre a história do Marquês de Rollebon. Em suas palavras:

Como me sinto longe deles, do alto deste outeiro! Parece-me que pertenço a outra espécie. Vão sair dos escritórios, depois de um dia de trabalho; olham para as casas, para os jardins dos largos, com ar de satisfação; pensam que estão na "sua" cidade, uma "bela urbe burguesa". Não têm medo, sentem-se em casa. (...) É gente sossegada, um pouco taciturna; pensa no dia de amanhã, isto é, simplesmente um novo hoje. (p. 97)

Sem a pretensão de estabelecer uma analítica inspirada em Sartre sobre as questões do presente artigo, o texto de Roquentin é apresentado apenas no ponto em que, nessa literatura, o estranhamento e o horror do protagonista à ordinariedade parece apresentar certa aproximação ao mal-estar do suicídio emocional da conformidade. Como se pertencendo à "outra espécie", autogestada e assimétrica em relação ao universo das regularidades normais e vazias de sentido, a realidade discursivo-imaginária das modificações corporais extremas parece partilhar, com o protagonista, de semelhante náusea e recusa à experimentação do "dia de amanhã" como mera repetição do mesmo, "um novo hoje".

Na saga de Roquentin, registrada num diário escrito com o propósito de "não deixar de escapar as diferenças do pormenor" (Sartre, 1938/2005, p. 2) de um dia a dia sem acontecimentos, o narrador chega à revelação de que "todo o existente nasce sem razão, prolonga-se por fraqueza e morre por acaso" (p. 168). O absoluto da contingência e o não sentido da existência é fio condutor de uma narrativa que nos levaria a supor que o protagonista, no 
momento de desfecho do romance, se renderia ao nada e ao desespero, ao desmedido da experiência da negatividade. Contudo, eis que somos surpreendidos com um desejo pela literatura como um destino possível à inadequação fundamental do narrador. Em suas palavras:

O meu erro era o de querer ressuscitar o sr. de Rollebon. Outra espécie de livro. Não sei muito bem qual - mas era preciso que se adivinhasse nele, por trás das palavras impressas, por trás das páginas, alguma coisa que não existisse, que estivesse acima da existência. Uma história, como por exemplo, uma aventura. Era preciso que fosse bela e dura como aço e que fizesse vergonha às pessoas da sua existência. (p. 221)

Assim, em meio à tonalidade solitária, monocromática e desencantada da escrita diaresca de Roquentin, eis que surge a perspectiva da escrita de uma aventura, indefinida, que emergisse como algo fantástico/ficcional, alguma coisa que não existisse, que estivesse acima da existência. $\mathrm{O}$ ineditismo, a unicidade, a singularidade da produção literária almejada parece, desse modo, oferecer alguma voz de resposta à ânsia do protagonista de estabelecer uma ruptura com o universo da alteridade amorfa, torporosa, meio a dormir do homem médio de Bouville. Nesse desejo pela escrita, o narrador ainda adiciona os atributos de que a obra haveria de ser "bela e dura como aço e que fizesse vergonha às pessoas de sua existência" (p. 221). Ante a confrontação com a contingência da existência e sua fragilidade de sentidos, a dureza de aço, perene e reluzente, se ofereceria como esfera de registro, marcação e estabilidade possível à negatividade de sua existência. Inescapável ao olhar do outro, o narrador relata o seguinte devaneio acerca dos efeitos de seu livro sobre os outros:

E haveria pessoas que leriam esse romance e diriam: "Foi Antoine Roquentin quem o escreveu; era um fulano ruivo que andava sempre pelos cafés; e pensariam na minha vida, como eu penso na vida de tal negra: como em qualquer coisa de meio precioso e lendário". (p. 110)

Uma vida preciosa e lendária, antônima ao anonimato do "fulano ruivo", que guardava silenciosamente dentro de si, literalmente no corpo, no estômago, na náusea, a insustentável condição de ser "um rapaz sem importância coletiva; um indivíduo, nada mais". ${ }^{6}$ É na trilha desse desfecho, que o

${ }^{6}$ Citação da epígrafe do livro A náusea, autorada por Luis-Ferdinand Céline. 


\section{ARTIGOS}

desejo de Roquentin faria eco na experiência de leitura sobre os relatos autobiográficos dos sujeitos que recorrem às modificações extremas da imago corporal. $\mathrm{Na}$ aproximação proposta entre a paisagem narrativa discutida e o romance sartriano, a singularidade emerge como um sonho "lendário" de subversão ao Outro, uma formação mítica.

Entre a escrita de uma obra que tem o "aço" como metáfora, e o "corpo-obra-viva" adornado de joias feitas de aço (piercings), é de certo retorno da figura do "poeta-forte" (Rorty, 2007), que não se contenta em fazer variações

elegantes de poéticas passadas, que Roquentim parece dialogar com o problema do presente artigo.

\section{Indiferenciação e singularidade: a psicanálise crítica da cultura}

Sem dúvida, muito tempo se passou desde a escrita de "O mal-estar na civilização" (1930/1997). Dir-se-á que os conflitos dos modos de subjetivação atuais não poderiam ser mais descritos em termos do conflito entre pulsões sexuais vs cultura, e, menos ainda, no vocabulário da culpa e do remorso, efeitos da Lei do pai.

Nesse sentido, a prática das extremas modificações corporais, a cultura do espetáculo, a possibilidade de exibirmos nossas fantasias e disposições eróticas num contexto aparentemente bem mais libertário que o do ethos vitoriano do pai da psicanálise, seriam expressões significativas das radicais transformações operadas na cultura. A tese freudiana - sobre a constituição subjetiva embasada no lugar mítico-estrutural da função paterna - atravessaria, especialmente nos últimos cinquenta anos, um "franco declínio". Nessa perspectiva de leitura, a verticalidade do campo identificatório sustentado no Outro, como referência de autoridade representada nos ideais e interdições coletivamente partilhadas, não se constituiria mais como um campo consistente de investimento nos modos de subjetivação contemporâneos.

A renúncia a certa parcela do gozo e do autoerotismo, em prol da garantia de uma proteção face à nossa irreparável vulnerabilidade e desamparo, não passaria de um semblante. A crise das instituições tradicionais e, especialmente, a fragilização dos valores e da organização da família teriam produzido, marcadamente, uma geração desencantada com a verticalidade do poder paterno e desenganada de uma organização societal orientada por um Pai que representasse a Lei. O superego contemporâneo, muito diferentemente de uma instância restritiva/punitiva, seria incitativo/imperativo de um "mais gozar". 
Essa situação tem a angústia como pano de fundo, uma vez que o que predomina no laço e na relação com o Outro social é o desamparo capitalista que já passou da época do mal-estar e já entrou decididamente na época do impasse, particularmente visível no nível da ética. (Siqueira, 2009, p. 100)

Se o impasse supracitado tornou-se tão outro, ou se o mal-estar não tem mais o colorido da neurose histérica, não é objetivo específico da argumentação proposta. $\mathrm{O}$ intento do presente texto debruça-se sobre como no campo da atualidade discursiva problematizada parece formar-se uma ficção simbólico-imaginária, em que a diferenciação e a singularidade dispor-se-iam como pedra angular de um refúgio possível ao mal-estar na vida de relação com outro, par da cultura. Nesse sentido, torna-se importante destacar que a presente escrita afasta-se de uma psicanálise que se coloca como contemporânea, mas que insiste numa espécie de juízo de valor travestido de conceitos sobre as mutações culturais e subjetivas.

É cabível aqui, trazer as indagações do psicanalista Francisco Farias (2008) sobre a prática das extremas modificações corporais:

Aquele que trafega pelos recônditos do desejo do homem no seu processo incessante de busca de felicidade não pode evitar indagar-se: nas artes inscritas na corporalidade, o que causa um artista para que ofereça seu corpo, desvencilhando-se da dor, a múltiplas transformações, para criar um espetáculo que faz irromper, no espectador, angústia e horror? (p. 56)

Mais adiante no artigo, o autor indaga sobre quem representaria o Outro social para esse grupo, vez que, em sua leitura, a prática das modificações corporais, como uma forma de arte corporal, não teria a gratificação e o reconhecimento social como mecanismos reguladores. Sua apreensão de que as modificações corporais não se apoiariam em nenhum tipo de mecanismo sublimatório, simbolicamente estruturado, parece fazer coro junto à versão de uma psicanalista norte-americana, autora de uma publicação chamada Under the skin: A psychoanalytic study of body modification ${ }^{7}$ (Lemma, 2010). Logo na introdução do seu livro, lê-se a seguinte proposição:

Parte do problema deles [as pessoas que realizam modificações corporais extremas] é que eles não podem encontrar palavras para descreverem suas experiências e assim construir suas narrativas, as quais poderiam libertá-los da

7 "Sob a pele: um estudo psicanalítico sobre as modificações corporais" (tradução minha). 


\section{ARTIGOS}

concretude da existência confinada num corpo para um, ao invés de habitar um corpo para dois - um comunicativo, diádico corpo. ${ }^{8}$ (p. 8)

As interpretações dos autores acima mencionados, que encampam de modo bastante generalizante a diversidade subjetiva referente ao grupo de sujeitos que realizam as marcações corporais, parecem insistir na ideia de uma espécie de patologia da identificação ao Outro como mote de sua leitura sobre as condições de possibilidade da emergência do fenômeno em questão.

$\mathrm{Na}$ perspectiva argumentada no presente artigo, diferentemente de uma condição patologizante das identificações, talvez a dificuldade da psicanálise de nosso tempo centrar-se-ia na resistência em reconhecer uma nova linguagem para os processos identitários. Desse modo, o recurso à singularidade como vetor discursivo de um corpo suporte da existência, sustentar-se-ia não num impasse da ordem da "falta do pai" — posto que este é sempre um pai morto, condição para a subjetivação na linguagem - mas de outros modos de registro, transmissão e subversão da história de si, história essa sempre tributária à alteridade.

Por vezes, a intensidade das versões sobre a função paterna como princípio adoecedor, por sua carência, da subjetividade contemporânea, e simultaneamente seu suposto remédio, provocava a imagem de que, num cenário tão devastado em sua potência de simbolização, nossa condição cultural estaria próxima à paisagem do primeiro tempo da horda primeva, excetuados do campo da linguagem, fruindo de gozos puramente autoeróticos, num abismal vazio alteritário. Seria um tempo de primazia de Tanatos sobre Eros. A exemplo dessa modalidade interpretativa apresenta-se a seguinte citação, do artigo de Farias (2008), apontado anteriormente:

É como se o corpo fosse arrancado das malhas do simbólico e lançado no Real sem qualquer véu imaginário. Não só do corpo subtrai-se a dor, como do sujeito é subtraído o corpo, na sensação singular vivida pelo sujeito, quando coloca seu corpo em suspensão, no duplo sentido do termo. (p. 55)

Numa apreensão lacaniana do mito freudiano, o traço unário é concebido em termos da pré-condição à ordem significante, alicerce da conjectura histórica sobre a gênese da escrita (Lacan 1960-1961/1992). Sua

${ }^{8}$ Citação original: "Part of their problem is that they cannot find words to describe their experience and so construct their narratives, which would free them from the concreteness of existence within the confines of a body for one, instead to inhabit a body for two - a communicative, dyadic body. 
inscrição original seria sígnica, pois no primeiro momento do mito esse seria um representante do assassinato do pai. "Só depois", num segundo momento, quando se opera a série de atos, o traço advém como significante, a partir do qual os demais significantes se inscrevem. Nesse sentido, sua condição primeira, de signo, se apagaria. O traço viria, assim, nomear a mínima diferença entre significantes. Essa seria a condição de estabelecimento de uma série de significantes, no qual um sujeito se representa para o outro, formando o laço social.

O laço social propriamente dito pressupõe o estabelecimento da série significante, em que o ideal do eu não se encontra encarnado em alguém ou algo, mas permanece como uma capacidade de deslocamento própria à sua função de representação. (Poli, 2004, p. 44)

É curioso pensar que o ideal do eu, em seu atributo metonímico, de deslizamento significante, pode vir a assumir, em diferentes épocas, lugares-significantes diversos não fixados em valores que habitualmente identificaríamos como verticais. Num momento histórico de fortes injunções de massificação midiática e econômica, de novos dispositivos de controle imagético e social (panópticos digitais), não seria estranho supor que a singularidade pudesse vir a ocupar outro lugar na escala de valores de nosso tempo. A exposição do corpo ao olhar de um outro anônimo nunca foi tão vivenciada e, simultaneamente, vigiada. Nos perfis de redes de relacionamento virtuais, nos registros em fotografias digitais postadas à nossa revelia na internet, nas câmeras de controle de segurança, nos cadastros de instituições das quais o sujeito participa, a imagem do corpo nunca foi passível de tamanha circulação, manipulação e avaliação por um Outro desconhecido.

Nesse cenário, visibilidade e anonimato parecem formar um par dialógico de um jogo espetacular interminável, em que os participantes experienciariam pouco ou nenhum controle sobre suas regras. $\mathrm{O}$ excedente de visão, o campo cego da imagem insondável que é feita de nós, é objeto do mais intenso investimento das preocupações contemporâneas. Inserido numa serialidade cada vez mais superpovoada, anônima e urbana, o grupo investigado idealiza a subjetividade que reconhece na diferenciação seu traço identitário. Nessa paisagem discursiva, as modificações corporais emergem como insígnia de uma bravura hercúlea, em seu intento imaginário de poder produzir algum campo de registro estável de sua biografia e negatividade, ainda que grafado, paradoxalmente, na breve longevidade da pele.

A singularidade, registrada na superfície do corpo discursivamente constituído, encenaria um possível ideal de estetização da existência num 


\section{ARTIGOS}

movimento de resistência à captura mortífera pelo olhar do Outro que sempre anularia o desejo do sujeito de ser "mais um especial" na serialidade da ordem simbólica. Esse ideal teria sua verticalidade produzida não pelo tradicional discurso da autoridade e consequente submissão subjetiva, mas pela via do embate à aproximação do sonho mítico e, partilhado culturalmente, de legitimação da diferença, de tornar-se, no vocabulário de Rorty (2007), o "poeta forte" de seu tempo, de sua existência, portador de um nome próprio.

No campo das identificações imaginárias, horizontais, o processo identificatório não seria regido, mais incisivamente, pela Lei que estabiliza e pacifica as relações entre os irmãos na organização paterna. Nesse plano identificatório, duas possibilidades não excludentes podem ser vislumbradas. Uma delas constituiria um tipo de laço sustentado na função que o outro semelhante desempenharia em fazer força ante a arbitrariedade regulatória do Outro. É como se o eterno apelo de reconhecimento dirigido ao Outro encontrasse no irmão outra possibilidade de legitimação da diferença (Kehl, 2000). Nesse universo, o amparo fraternal abrigaria, enquanto modalidade de ética solidária, o poder de coibir e/ou amortecer os abusos paternos. Neste registro, para muito além da rivalidade entre os irmãos apontada por Freud (1930/1997), aconteceria o espaço para outras formas de sociabilidades, bem como a produção de novas práticas linguageiras, transformadoras dos discursos estabelecidos na cultura, geradoras das diversas formas de contestação política e moral.

Numa segunda acepção para as identificações horizontais, o espaço fraterno seria um campo identificatório formado pelo desejo de passar ao largo da função paterna. Nesse cenário que reedita a brutalidade do arbítrio do pai da horda, o outro, em sua organização coletiva, fundaria uma espécie de exceção delinquente e perversa, produtora dos diversos modos de narcisismo das pequenas diferenças. O elemento aglutinador dos pares se daria não pelo traço unário, mas pelos traços de gozos e do culto à imagem. Nesse tipo de formação, a paixão devotada à causa partilhada como identidade grupal seria expressão da rigidez própria à totalização imaginária do clã.

Afirmar que as subjetividades, implicadas nas práticas das extremas modificações corporais da contemporaneidade, situam-se nessa ou naquela modalidade identificatória é generalização problemática, visto que o ato de marcar-se per si nada diz, como também sabemos que um sintoma não é formação de equivalência unidirecional a determinado modo de relação com a alteridade. Contudo, a partir dos lugares-significantes através dos quais o Outro parece posicionar-se no discurso em discussão, o presente artigo 
arrisca-se a ficcionar sobre os possíveis princípios identificatórios que participariam dessa realidade discursiva.

Situar, assim, o princípio identificatório do grupo investigado no modelo da "exceção perversa", aniquiladora da alteridade como o pai primevo e concentrada no traço de fruição do gozo seria, na leitura aqui proposta, um modo de patologização psicanalítica das mutações subjetivantes. Enfatizar a primazia de uma identificação horizontal, regressiva e mortífera, em conformidade ao estilo intolerante das gangs, ou, ainda, das comunidades de adictos, parece leitura que erradica qualquer positividade discursiva e transformadora à paisagem subjetiva investigada no presente texto.

Devemos investigar melhor afirmações, cada vez mais recorrentes na literatura psicanalítica atual, segundo as quais estaríamos passando por mutações profundas no impacto psíquico das exigências presentes nos vínculos sociais. A esse respeito, ouvimos várias vezes que a perversão estaria se tornando o saldo hegemônico dos processos de socialização. Infelizmente, muitas vezes colocações desta natureza são apenas versões modernizadas da crítica moral à sociedade contemporânea com seu pretenso hedonismo excessivo, sua recusa a aceitar a castração e a impossibilidade do gozo. (Safatle, 2010, p. 102)

Nesse sentido, o reconhecimento de certa dimensão fetichizante da imago corporal e da singularidade, não pode ser assumido como evidência de uma disposição regressiva, pré-edipiana. Nos relatos investigados (Pinheiro, 2011), se identificamos certo investimento fálico nas modificações corporais, uma espécie de traço onipotente, imaginarizante da singularidade, tal posição enunciativa não necessariamente implica regressões subjetivas excetuadas da ordem significante. Pelo contrário, seria apenas como uma "ilusão necessária" à possibilidade de trafegação identitária numa cultura desencantada dos tradicionais sentidos doadores da existência, que a singularidade discutida, mesmo guardando alguns atributos de totalização narcísica, não deixa de articular, simbolicamente, novas formas de vínculo com o Outro social.

Retornando ao que Freud (1930/1997) assinalou sobre o mal-estar na cultura, a organização patriarcal da sociedade haveria provido uma eficiente, porém extremamente custosa, forma de descentração da onipotência humana. Nessa estrutura, o sujeito estaria irremediavelmente lançado ao tenso conflito entre a manutenção do princípio de equivalência para com o outro, a que Freud teria chamado de "instituição da justiça", e o retorno do seu dark side, sua dimensão transfigurante e inimiga do pacto social, referente à força da onipotência infantil (Whitebook, 1995). Por esse caminho, quaisquer alternativas de transformação radical da sociedade que não incluam um mecanismo 


\section{ARTIGOS}

de descentração do imaginário onipotente do homem estariam fadadas a tornarem-se uma mera utopia.

No contexto do problema argumentado, o embate conflitivo, aludido acima, não deixa de fazer sua marca nas escritas analisadas. A proposição da singularidade como um ideal recorrente nos relatos, como formação do inconsciente, necessariamente implicará reconhecê-la como uma composição híbrida, de registros antitéticos: negação e afirmação da castração.

\section{Referências}

Birman, J. (1996). Por uma estilística da existência. São Paulo, SP: Ed. 34.

Correia, A. F. (2001). O mito individual como estrutura subjetiva básica. Psicologia: Ciência e Profissão, 21, 58-69.

Costa, J. (2004). O vestígio e a aura - corpo e consumismo na moral do espetáculo. Rio de Janeiro, RJ: Garamond.

Cuéllar, D. P. (2010). From the conscious interior to an exterior unconscious - Lacan, discourse analysis and social psychology. Londres: Karnac Books.

Freud (1997). O mal-estar na civilização. In Edição Standard Brasileira das Obras Psicológicas Completas de Sigmund Freud (Vol. 21). Rio de Janeiro, RJ: Imago. (Trabalho original publicado em 1930).

Farias, F. R. (2008). Carne, pele e corpo desencarnado: o desvelar do objeto "a" na body art. Tempo psicanalítico, 40(1), 41-58.

Foucault, M. (1992). Vigiar e punir - História da violência nas prisões. Petrópolis, RJ: Vozes.

Kehl, M. R. (2000). Existe a função fraterna? In M. R. Kehl, Função fraterna (pp. 31-47). Rio de Janeiro, RJ: Relume-Dumará.

Lacan, J. (1992). O seminário. Livro 8. A transferência. Rio de Janeiro, RJ: Jorge Zahar. (Trabalho original publicado em 1960-1961).

Lacan, J. (2008). O mito individual do neurótico. Rio de Janeiro, RJ: Jorge Zahar. (Trabalho original publicado em 1981).

Laplanche, J., \& Pontalis, J.-B. (1998). Dicionário da psicanálise. São Paulo, SP: Martins Fontes.

Lemma, A. (2010). Under the skin: A psychoanalytic study of body modification. London: Routledge.

Pinheiro, M. (2009). Formações do inconsciente: ressonâncias da metáfora no leitor. Trieb, 1(1), 273-279. 
Pinheiro, M. (2011). Singularidade e corpo: uma questão para a subjetividade. Tese de Doutorado, UFPE, Recife.

Poli, M. C. (2004). Perversão da cultura, neurose do laço social. Ágora, VII(1), 39-54.

Rorty, R. (2007). Contingência, ironia e solidariedade. São Paulo, SP: Martins.

Safatle, V. (2010). Fetichismo: colonizar o outro. Rio de Janeiro, RJ: Civilização Brasileira.

Sartre, J. P. (2005). A náusea. Rio de Janeiro, RJ: Nova Fronteira. (Trabalho original publicado em 1938).

Siqueira, E. (2009). O estatuto contemporâneo das identificações em sujeitos com marcas e alterações corporais. Dissertação de Mestrado, UNICAP, Recife.

Souza, A., \& Rocha, Z. (2009). No princípio era o mythos: articulações entre mito, psicanálise e linguagem. Estudos em Psicologia, 14(3), 199-206.

Sweetman, P. (1999). Anchoring the (Postmodern) self? Body modification, fashion and identity. Body and Society, 5(2-3), 51-76.

Vanier, A. (2005). Lacan. São Paulo, SP: Estação Liberdade

Zizek, S. (2007). Tolerance as an ideological category. Critical Inquiry, Autumn-2007. Recuperado de: <http://www.lacan.com/zizek-inquiry.html>.

Whitebook, J. (1995). Perversion and utopia: a study in psychoanalysis and critical theory. Massachussets: MIT Press.

\section{Resumos}

(Singularity and myth: the body as a subversive power)

Based on analysis of narratives that are typical of subjects who perform extreme body modifications (establishing body images that differ from classic Western standards through excessive use of techniques such as tattoos, piercings and plastic surgery), this paper questions singularity, considering it a basis of mythical and imaginary formation, in which someone's unicity is an anchor of identity and a possible expression of the desire to become the strong poet of his or her own story.

Key words: Singularity, culture, splitted subject, extreme body modifications, myth

(Singularité et mythe: Le corps comme puissance subversive)

Au moyen d'une recherche sur le champ énonciatif de sujets qui effectuent des modifications corporelles extrêmes (construction d'une image corporelle différente du modèle occidental classique, marquée par l'usage excessif de techniques telles que le tatouage, le piercing et la chirurgie plastique), cet article discute la singularité en 


\section{ARTIGOS}

tant que formation mythico-imaginaire, dans laquelle l'unicité de l'être serait non seulement un ancrage de l'identité, mais aussi une expression possible du désir de devenir le poète fort de sa propre histoire.

Mots clés: Singularitésé, sujet divisé, modifications corporelles extrêmes, mythe

(Singularidad y Mito: El cuerpo como fuerza subversiva)

Através de la investigación sobre el campo enunciativo propio de los sujetos que se realizan modificaciones corporales extremas (construcción de la imagen corporal diferente al estándar clásico occidental, con el uso excesivo de técnicas como: tatuaje, piercing y cirugía plástica), el presente artículo problematiza la singularidad, tomándola en la condición de una formación mítico-imaginaria, en la cual la unicidad del ser sería, no solamente, un anclaje identitario, sino también una posible expresión del deseo de convertirse en el poeta fuerte de su historia.

Palabras clave: Singularidad, sujeto dividido, modificaciones corporales extremas, mito

(Singularität und Mythos: der Körper als subversives Potenzial)

Durch die Forschung auf dem Gebiet des Selbstausdrucks von Subjekten die extreme körperliche Veränderung durchgehen (Konstruktion eines Erscheinungsbildes welches vom klassischen westlichen Muster abweicht, wie z.B. durch die übertriebene Anwendung von Tätowierungen, Piercings und/oder plastischer Chirurgie), problematisiert der vorliegende Artikel Singularität indem er diese als mythisch-imaginäres Konstrukt betrachtet. Die Einzigkeit des Selbst ist hier nicht nur eine identitärische Verankerung, sondern auch der mögliche Ausdruck des Wunsches, der Poet seiner eigenen Geschichte zu sein.

Schlüsselwörter: Singularität. geteiltes Subjekt. extreme körperliche.

Veränderungen, Mythos

Citação/Citation: Pinheiro, M., \& Carvalho, G. (2017, dezembro). Singularidade e mito: corpo como porência subversiva. Revista Latinoamericana de Psicopatologia Fundamental, 20(4), 728-748. http://dx.doi.org/10.1590/1415-4714.2017v20n4p728.7.

Editores do artigo/Editors: Profa. Dra. Ana Maria Rudge e Profa. Dra. Sonia Leite.

Recebido/Received: 12.4.2017/ 4.12.2017 Aceito/Accepted: 8.6.2017 / 6.8.2017

Copyright: (C) 2009 Associação Universitária de Pesquisa em Psicopatologia Fundamental/ University Association for Research in Fundamental Psychopathology. Este é um artigo de livre acesso, que permite uso irrestrito, distribuição e reprodução em qualquer meio, desde que o autor e a fonte sejam citados / This is an open-access article, which permits unrestricted use, distribution, and reproduction in any medium, provided the original authors and sources are credited. 
Financiamento/Funding: As autores declaram não terem sido financiadas ou apoiadas. The authors have no support or funding funded to report.

Conflito de interesses/Conflict of interest: As autorss declaram que não há conflito de interesses / The authors have no conflict of interest to declare.

\section{Marina Pinheiro}

Professora do Departamento de Psicologia da Universidade Federal de Pernambuco UFPE (Recife, PE, Br); Doutora em Psicologia Cognitiva pela mesma Universidade e mestre em Psicologia Clínica pela Universidade Católica de Pernambuco - UNICAP (Recife, PE, Br).

Avenida Professor Moraes Rego, 1235, Centro de Filosofia e Ciências Humanas, $9^{\circ}$ Andar, Cidade Universitária

Recife, PE, Br.

marinaassis.pinheiro@gmail.com

\section{Glória Carvalho}

Professora do Programa de Mestrado em Ciências da Linguagem da Universidade Católica de Pernambuco - UNICAP (Recife, PE, Br); Doutora em Linguística pela mesma Universidade.

Rua Almeida Cunha, 245, Bloco G4, $8^{\circ}$ Andar, Setor A, Boa Vista

Recife, PE, Br.

gmmcarvalho@uol.com.br

This is an open-access article, which permits unrestricted use, distribution,

(cC) BY-NC and reproduction in any medium for non-commercial purposes provided the original authors and sources are credited. 